\title{
Comparative study of three types of controllers for DFIG in wind energy conversion system
}

\author{
Saïd Boubzizi ${ }^{1,2^{*}}$, Hafedh Abid ${ }^{1}$, Ahmed El hajjaji ${ }^{2}$ and Mohamed Chaabane
}

\begin{abstract}
This paper presents an enhanced control strategy for Wind Energy Conversion System (WECS) using Doubly-Fed Induction Generator (DFIG). A robust Super-Twisting (STW) sliding mode control for variable speed wind turbine is developed to produce the optimal aerodynamic torque and improve the dynamic performance of the WECS. The electromagnetic torque of the DFIG is directly tracked using the proposed control to achieve maximum power extraction. The performance and the effectiveness of the STW control strategy are compared to conventional Sliding Mode (SM) and Proportional-Integral (PI) controllers. The proposed STW algorithm shows interesting features in terms of chattering reduction, finite convergence time and robustness against parameters variations and system disturbances.
\end{abstract}

Keywords: Wind turbine (WT), Doubly-fed induction generator (DFIG), Power generation, STW (super-twisting), Second order sliding mode control (SOSMC), PI controller

\section{Introduction}

Over the last decade, wind energy has taken an increasingly important place in the field of electric energy generation. This kind of energy source is developed due to the global growing of electricity demand and the trend towards renewable and non-polluting energy sources in the world [1]. Indeed, in wind energy conversion system (WECS), the maximum wind power could be extracted when the tip-speed-ratio of the turbine is maintained at its optimum value for different wind speed patterns [2]. Thus, it is necessary to develop more advanced control strategies for WECS. To this end, several control methods have been designed and implemented for wind energy generation such as, vector control which is based on voltage and flux oriented vector using the d-q rotating frame to decouple the active and reactive power, $[3$, 4]. In fact, this strategy is sensible to parameters variations of the system such as resistance and inductance variations. To overcome this problem, direct torque

\footnotetext{
* Correspondence: saidboubzizi@yahoo.fr

${ }^{1}$ Lab-STA Laboratory, National Engineering School of Sfax, Route de la Soukra, 3029 Sfax, Tunisia

${ }^{2}$ MIS Laboratory, University of Picardie Jules Verne, 33, Rue Saint-Leu, 80039 Amiens, France
}

control (DTC) has been introduced by $[5,6]$ to directly control generator torque and stator flux using a predefined lookup table based on the estimation of the stator flux and electromagnetic torque. Direct power control (DPC) proposed in [7], has used the same concept of the DTC method. DPC control strategy is based on decoupling and direct control of reactive and active power [8]. In fact, the non-linear behaviors of mechanical and electrical parts of WECS as well as variations of electromechanical parameters represent crucial problems [9]. In addition, wind turbine (WT) works under high wind speed variations, which makes its control a serious challenge [10]. As result, several nonlinear control techniques have been developed in the literature for WT, such as fuzzy logic [11], neural networks [12], and high-order sliding mode control [13].

Currently, most WECS use Double feed induction generator (DFIG). This is due to many advantages such as variable speed operation of the generator $( \pm 30 \%$ around the synchronous speed), decoupling between active and reactive powers, maximization of energy generation and competitive price [1]. But, DFIG is subjected to many constraints, such as the effects of parametric variations and the disturbance of the wind speed, which 
could deviate the system from its optimal operation point. Many control techniques of the DFIG have been presented with different control schemes. The conventional Proportional-Integral (PI) controller, although widely used in many control applications [14], requires adjustment for every change in reference patterns. Another main disadvantage of this controller is its sensibility to external disturbances and parameters variations. Because of the frequent uncertainty in wind speed variations, this type of conventional controller fails to give quality power generation and tracking references given by an MPPT. Predictive control based on rotor voltage and stator power equations for direct power control, is proposed in $[15,16]$. Nevertheless, the calculated output reactive and active power which depend on the generator parameters as well as the time calculation, are the main drawbacks of this method [17]. In addition, internal uncertainties and external disturbances produce serious oscillations of the WECS. To ensure the robustness of the system against parametric variations and external disturbances, the authors in $[18,19]$ have introduced sliding mode control (SMC). In fact, SMC could achieve active and reactive power tracking and improve the dynamic.

behaviour of the WT [20]. Second order sliding mode control (SOSMC) could guarantee the same performance of classical SMC with its ability to overcome the chattering problem [21]. The main contribution of this paper, which deals with WECS based on DFIG, consists in developed and compared the performances and the robustness of three types of controllers for the DFIG with aerodynamic torque estimation. In this paper, a high order SMC is used to improve the dynamic performances of WECS by producing the required electromagnetic torque under different wind speed patterns. The desired DFIG torque is directly tracked to achieve maximum power extraction. In order to prove the robustness performance of the proposed controller, its dynamic behaviour is compared with the conventional Sliding Mode (SM) and Proportional-Integral (PI) controllers under high wind speed variations. The simulation results show that high order SMC is an interesting method to control WECS based on DFIG.

This paper is organized as follow: Section 2 recalls a short overview of first order sliding mode control and second order sliding mode control. In the Section 3, we present the structure of wind energy conversion system then the modelling of turbine and the double feed induction generator. In the first part of Section 4, we present the estimation of the aerodynamic torque. In the second part of Section 4, we describe the control of the aerodynamic torque. In Section 5, we interest to the control of DFIG. In this context, we compare three types of controllers such as PI, sliding mode control and second order sliding mode control. Finally, Section 6 shows the simulation results of the proposed system.

\section{Sliding mode control strategy}

\subsection{First order sliding mode control}

Sliding mode control is a powerful nonlinear control, which has been analyzed by many researchers. The sliding mode control law includes two main parts [22]:

$$
V=V^{e q}+V^{n}
$$

$V^{e q}$ is called equivalent control and $V^{n}$ is known as switching control signal.

We consider the following sliding surface, [23]:

$$
S(X)=\left(\frac{d}{d t}+\lambda\right)^{n-1} e
$$

where, $e=X_{d}-X$ is the error of the signal to be adjusted, $\lambda$ is a positive coefficient and $n$ is the system order.

The main target in this methodology is to keep $S(X)=$ 0 and $\dot{S}(X)=0$.

The reaching condition is given by the following equation:

$$
S(X) \dot{S}(X) \leq 0
$$

\subsection{Second order sliding mode control}

As well known, classical sliding mode method generates undesirable chattering effect which can be harmful for the system, SOSMC can only attenuate this problem. Therefore, Super-Twisting (STW) strategy is nowadays preferable over the classical siding mode, since it eliminates the chattering phenomenon.

Let us consider the following nonlinear system

$$
\dot{S}(X)=f(t, S)+u
$$

where, $f(t, S)$ is an unknown bounded perturbation term, with $|f(t, S)|<\delta|S|^{1 / 2}$ for some constant $\delta>0$.

The STW sliding mode control for perturbation and chattering elimination is given by the next algorithm:

$$
\left\{\begin{array}{l}
u=v-a_{1}|S|^{1 / 2} \operatorname{sgn}(S) \\
\dot{v}=-a_{2} \operatorname{sgn}(S)
\end{array}\right.
$$

where, $a_{1}$ and $a_{2}$ are fixed gains.

From Eqs. (4) and (5), we can deduce

$$
\left\{\begin{array}{l}
\dot{S}=v+f(t, S)-a_{1}|S|^{1 / 2} \operatorname{sgn}(S) \\
\dot{v}=-a_{2} \operatorname{sgn}(S)
\end{array}\right.
$$

The stability analysis of system (6), can be proved using the following Lyapunov candidate function 


$$
V=2 a_{2}|S|+\frac{1}{2} v^{2}+\frac{1}{2}\left(a_{1}|S|^{1 / 2} \operatorname{sgn}(S)-v\right)^{2}
$$

To guarantee $\dot{V}<0$, the controller gains must satisfy the following conditions, [24].

$$
a_{1}>2 \delta, \quad a_{2}>a_{1} \frac{5 \delta a_{1}+4 \delta^{2}}{2\left(a_{1}-2 \delta\right)}
$$

The controller gains $a_{1}$ and $a_{2}$ are designed in order to fulfill the previous conditions and to ensure low content of high frequency components in the control. Indeed, a high gains values can lead to high chattering effects and poor performance.

\section{System description}

The most popular configurations of Wind Energy Conversion Systems (WECS) use the DFIG, as shown in Fig. 1. In this configuration, the wind turbine rotates with variable wind speed. It converts first the kinetic power into mechanical power then into electrical power through the generator (DFIG).

The expression of the aerodynamic power is given by the following Eq. [8]:

$$
P_{a}=\frac{1}{2} \pi R^{2} \rho C_{p}(\lambda) v^{3}
$$

where, $v, R, C_{p}(\lambda)$ denotes respectively the wind speed, the radius, and the power coefficient of the turbine.

The tip-speed ratio is defined as follows:

$$
\lambda=\frac{R \Omega_{r}}{v}
$$

The extraction of aerodynamic power depends mainly on the available wind speed, the characteristic power curve $\left(C_{p}\right)$ and the capacity of the wind turbine to respond to the changes in wind speed, as shown in Fig. 2.

The generator is coupled to the turbine through a gearbox whose ratio is given by the following equation:

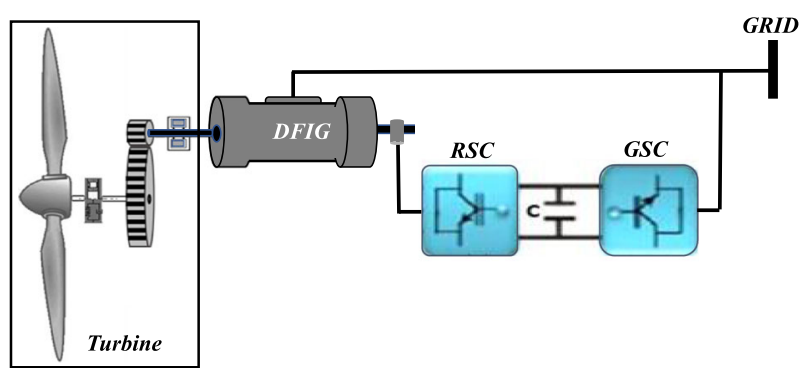

Fig. 1 WECS configuration based on DFIG

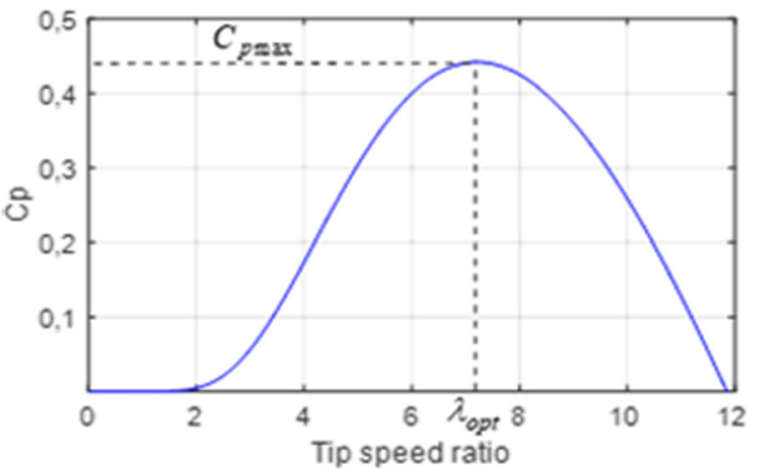

Fig. 2 WT power coefficient

$$
n_{g}=\frac{\Omega}{\Omega_{r}}
$$

The overall mechanical dynamics of WECS brought back to the turbine, which is represented by Fig. 3, can be expressed by the following equation [25]:

$$
\begin{array}{r}
J \dot{\Omega}_{r}=T_{a}-K \Omega_{r}-T_{g} \\
\text { with }\left\{\begin{array}{l}
J=J_{r}+n_{g}^{2} J_{g} \\
K=K_{r}+n_{g}^{2} K_{g} \\
T_{g}=n_{g} T_{e m}
\end{array}\right.
\end{array}
$$

where, $J, K$ and $T_{e m}$ respectively represent the overall inertia of WECS, the overall external damping of WECS and the electromagnetic torque of the generator.

\section{- DFIG modelling}

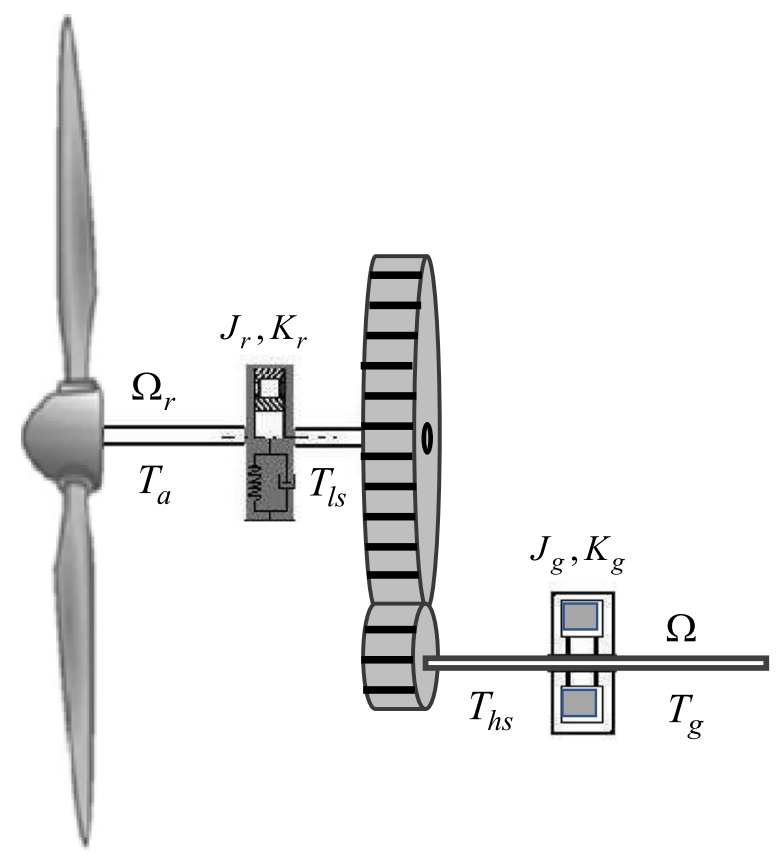

Fig. 3 Wind turbine drive train 
The electrical model of the DFIG in the d-q frame linked to the stator rotating field is given by the system (12), [26]:

$$
\left\{\begin{array}{l}
V_{s d}=R_{s} I_{s d}+\dot{\phi}_{s d}-\omega_{s} \phi_{s q} \\
V_{s q}=R_{s} I_{s q}+\dot{\phi}_{s q}+\omega_{s} \phi_{s d} \\
V_{r d}=R_{r} I_{r d}+\dot{\phi}_{r d}-\omega \phi_{r q} \\
V_{r q}=R_{r} I_{r q}+\dot{\phi}_{r q}+\omega \phi_{r d}
\end{array}\right.
$$

The flux linkages are given by system (13):

$$
\left\{\begin{array}{l}
\phi_{s d}=L_{s} I_{s d}+M I_{r d} \\
\phi_{s q}=L_{s} I_{s q}+M I_{r q} \\
\phi_{r d}=L_{r} I_{r d}+M I_{s d} \\
\phi_{r q}=L_{r} I_{r q}+M I_{s q}
\end{array}\right.
$$

The electromagnetic torque, active and reactive power developed by the DFIG can be expressed the following equations:

$$
\begin{aligned}
& T_{e m}=n_{p} \frac{M}{L_{s}}\left(I_{r d} \phi_{s q}-I_{r q} \phi_{s d}\right) \\
& P=V_{s d} I_{s d}+V_{s q} I_{s q} \\
& Q=V_{s q} I_{s d}-V_{s d} I_{s q}
\end{aligned}
$$

By using the field oriented control approach and neglecting stator resistance, we obtain, [27]:

$$
\left\{\begin{array}{l}
\phi_{s d}=\phi_{s}=c t e \\
\phi_{s q}=0 \\
\dot{\phi}_{s d}=0 \\
V_{s d}=0 \\
V_{s}=V_{s q}=\omega_{s} \phi_{s d}
\end{array}\right.
$$

and

$$
\left\{\begin{array}{l}
\dot{I}_{r d}=\frac{1}{\sigma L_{r}}\left(V_{r d}-R_{r} I_{r d}+s \omega_{s} \sigma L_{r} I_{r q}-\frac{M}{L_{s}} \dot{\phi}_{s d}\right) \\
\dot{I}_{r q}=\frac{1}{\sigma L_{r}}\left(V_{r q}-R_{r} I_{r q}-s \omega_{s} \sigma L_{r} I_{r d}-s \omega_{s} \frac{M}{L_{s}} \phi_{s d}\right)
\end{array}\right.
$$

Then, the active and reactive powers can be expressed as:

$$
\left\{\begin{array}{l}
P=V_{s q} I_{s q} \\
Q=V_{s q} I_{s d}
\end{array}\right.
$$

The expression of electromagnetic torque becomes:

$$
T_{e m}=k_{e} I_{r q}
$$

with, $k_{e}=-n_{p} \frac{M}{L_{s}} \phi_{s d}$.

\section{Control of the turbine}

In order to extract the wind energy, while ensuring the safety, the WT must operate in the second or third zone, as shown in Fig. 4.
The machine starts to work when the mechanical speed exceeds a certain speed $v_{c u t-i n}$. The main operating area can be distinguished as follows:

Zone 1: In this area, the WT is unable to generate any power.

Zone 2: This zone is limited by $v_{c u t-i n}$ and $v_{\text {rated }}$. In this area, the WT can operate with its maximum power coefficient $C_{p \max }$.

Zone 3: The WT produces the rated power. Beyond $v_{\text {cut_off }}$ an emergency device is activated to avoid damaging the system.

To ensure maximum efficiency of the WT, the power coefficient must be maintained at its maximum value in order to reach the optimal torque, which is given by the following equation:

$$
T_{\text {opt }}=k_{\text {opt }} \Omega_{r}^{2}
$$

where, $k_{\text {opt }}=\frac{1}{2} R^{5} \pi \rho \frac{C_{p \max }}{\lambda_{\text {opt }}^{3}}$.

The major problem of standard law is mainly the determination with accuracy the value of $k_{\text {opt }}$ since $\lambda_{\text {opt }}$ change significantly over time. To achieve WT power efficiency maximization, rotor speed should track the reference given by the optimum speed ratio, under variable wind speed and unknown aerodynamic torque. The wind speed variation would lead to aerodynamic power fluctuation and high mechanical effort, which results in less energy capture and poor performance in terms of active power generation. In the following, a second order sliding mode control (SOSMC) with aerodynamic torque observer is proposed.

\subsection{Torque estimation}

Aerodynamic torque $T_{a}(t)$ in Eq. (11), depends on the knowledge of the torque coefficient which is a difficult task to be achieved and not always available [28].

In this sense, an aerodynamic torque $\widehat{T}_{a}(t)$ observer based on STW algorithm is used, [21]:

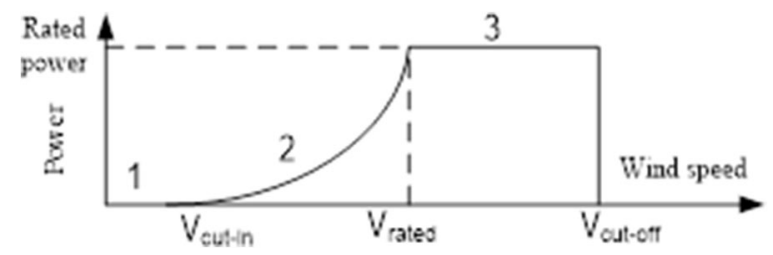

Fig. 4 Wind turbine control regions 


$$
\left\{\begin{array}{l}
\dot{\widehat{\Omega}}_{r}=\frac{\widehat{T}_{a}}{J}-\frac{K}{J} \Omega_{r}-\frac{T_{g}}{J}-a_{1}\left|\widehat{\Omega}_{r}-\Omega_{r}\right|^{1 / 2} \operatorname{sgn}\left(\widehat{\Omega}_{r}-\Omega_{r}\right) \\
\dot{\widehat{T}}_{a}=-\frac{a_{2}}{2} J \operatorname{sgn}\left(\widehat{\Omega}_{r}-\Omega_{r}\right)
\end{array}\right.
$$

where $a_{1}$ and $a_{2}$ are fixed gains.

The observation error is defined as follows:

$$
\sigma_{1}=\widehat{\Omega}_{r}-\Omega_{r}
$$

We assume that term $T_{a}(t)$ and its derivative are bounded with a known boundary which satisfies the following condition:

$$
\left|\dot{T}_{a}(t)\right|<J \Psi_{1}
$$

where, $\Psi_{1}$ is a positive constant.

Thus, we have

$$
\left\{\begin{array}{l}
\dot{\sigma}_{1}=-a_{1}\left|\sigma_{1}\right|^{1 / 2} \operatorname{sgn}\left(\sigma_{1}\right)+\eta \\
\dot{\eta}=-\frac{a_{2}}{2} \operatorname{sgn}\left(\sigma_{1}\right)-\frac{\dot{T}_{a}}{J}
\end{array}\right.
$$

where, $a_{1}$ and $a_{2}$ verify the following inequalities:

$$
\left\{\begin{array}{l}
a_{1}>\Psi_{1} \\
a_{2}>\sqrt{4 \Psi_{1} \frac{a_{1}+\Psi_{1}}{a_{1}-\Psi_{1}}}
\end{array}\right.
$$

Thus, we can guarantee the convergence of $\sigma_{1}$ and its derivative to zero in a finite time $t_{F}$.

\subsection{Aerodynamic torque control}

In this section, our control objective is to achieve maximum power extraction while maintaining the security regime of the WECS, as illustrated in Fig. 4 by converging $\widehat{T}_{a}$ to $T_{\text {opt }}$. We consider the following tracking error:

$$
\sigma_{2}=T_{o p t}-\widehat{T}_{a}
$$

The derivative of Eq. (25) is:

$$
\dot{\sigma}_{2}=2 k_{o p t} \frac{\Omega_{r}}{J}\left(\widehat{T}_{a}-K \Omega_{r}-T_{g}\right)-\dot{\widehat{T}}_{a}
$$

Then, we define the following functions:

$$
\left\{\begin{array}{l}
A=2 k_{o p t} \frac{\Omega_{r}}{J} \\
B=2 k_{o p t} \frac{\Omega_{r}}{J}\left(\widehat{T}_{a}-K \Omega_{r}\right)-\dot{\widehat{T}}_{a}
\end{array}\right.
$$

We assume that $B\left(\Omega_{n}, t\right)$ is bounded, $B\left(\Omega_{n}, t\right) \prec \Psi_{2}$ where $\Psi_{2}$ is a positive constant.

Thus, Eq. (26) can be written as follows:

$$
\dot{\sigma}_{2}=B\left(\Omega_{r}, t\right)-A\left(\Omega_{r}, t\right) T_{g}
$$

We consider the following STW algorithm based on second order sliding mode approach, given by the following equations:

$$
\left\{\begin{array}{l}
T_{g}=y+b_{1}\left|\sigma_{2}\right|^{1 / 2} \operatorname{sgn}\left(\sigma_{2}\right) \\
\dot{y}=\frac{b_{2}}{2} \operatorname{sgn}\left(\sigma_{2}\right)
\end{array}\right.
$$

where gains $b_{1}$ and $b_{2}$ satisfy the following inequalities:

$$
\left\{\begin{array}{l}
b_{1}>\Psi_{2} \\
b_{2}>\sqrt{4 \Psi_{2} A_{\max } \frac{b_{1}+\Psi_{2}}{b_{1}-\Psi_{2}}} \\
0<A_{\min } \leq A \leq A_{\max }
\end{array}\right.
$$

In this section, we have proposed a robust control strategy of the WT with aerodynamic torque estimation to achieve maximum power extraction. In the next section, we will tackle the control of the electrical part of our system (DFIG).

\section{Control of the DFIG}

In this section, we will interest in the control strategy of the generator, as shown in Fig. 5. In this sense, three types of controllers are developed and compared namely PI, first order SMC and SOSMC, for the DFIG.

Based on Eqs. (13), (15) and (17), the reactive power can be written as follows:

$$
Q=\frac{V_{s}}{L_{s}}\left(\phi_{s}-M I_{r d}\right)
$$

The reference current $I_{r d}$, ref can be deduced from Eq. (31) by keeping the desired reactive power $Q=0$.

$$
I_{r d, r e f}=\frac{\phi_{s}}{M}=\frac{V_{s}}{\omega_{s} M}
$$

The main objective is to maximize wind power generation by reaching optimal torque $T_{r e f}$.

However, we need to use two controllers. The first is placed in the $d$ axe to keep the reactive power at zero, the second is placed in the $\mathrm{q}$ axe to obtain the optimal torque.

Let's consider the following errors:

$$
\left\{\begin{array}{l}
\sigma_{I r d}=I_{r d}-I_{r d \_r e f} \\
\sigma_{T e m}=T_{e m}-T_{r e f}
\end{array}\right.
$$

\subsection{PI controller}

By applying the field oriented control approach to the DFIG, the equations along the two axes $d$ and $q$ will be decoupled by compensating the coupling terms. 


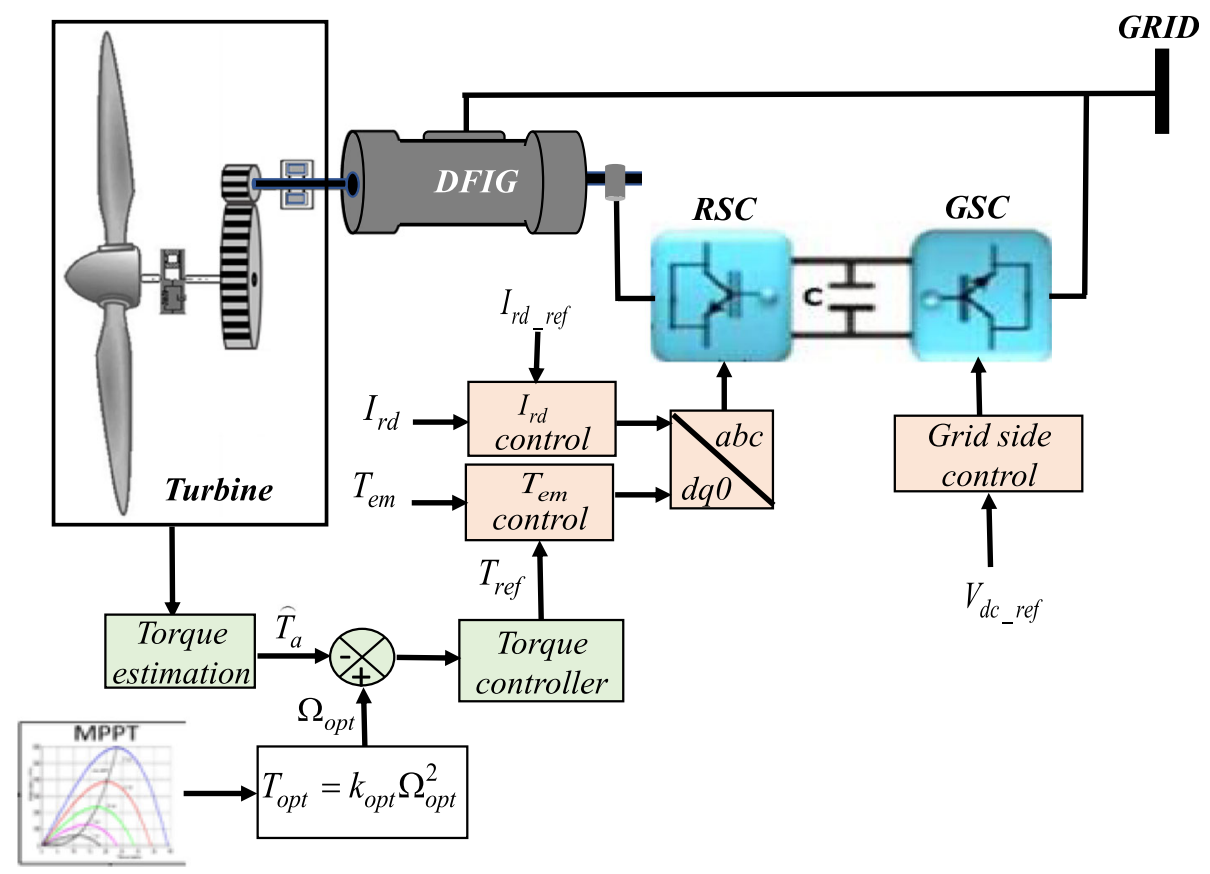

Fig. 5 WT-DFIG control strategy

The closed-loop control scheme diagrams along the $\mathrm{d}$ and $\mathrm{q}$ axes are similar. They are given by the following figures:

The parameters of the PI controller, $K_{p}$ and $K_{i}$, can be computed using pole compensation approach. However, it is important to specify that the pole compensation is not the only method to compute the PI parameters. The calculation of the controller parameters must compensate the most dominant pole of the transfer function.

Let's consider the case of $I_{r d}$ control as shown Fig. 6 whose open loop transfer function is written as follows:

$$
G(p)=\frac{K_{p}}{p}\left(p+\frac{K_{i}}{K_{p}}\right) \frac{L_{s}}{\left(L_{s} L_{r}-M^{2}\right)\left(\frac{L_{s} R_{r}}{L_{s} L_{r}-M^{2}}+p\right)}
$$

To eliminate the zero of the transfer function, we choose:

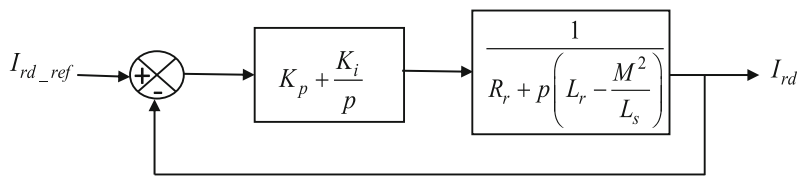

Fig. $6 I_{r d}$ control

$$
\frac{K_{i}}{K_{p}}=\frac{L_{s} R_{r}}{L_{s} L_{r}-M^{2}}
$$

Then, Eq. (34) becomes:

$$
G(p)=\frac{K_{p}}{p} \frac{L_{s}}{\left(L_{s} L_{r}-M^{2}\right)}
$$

The closed loop transfer function is expressed by:

$$
H(p)=\frac{1}{1+\tau p}
$$

with

$$
\tau=\frac{L_{r} L_{s}-M^{2}}{K_{p} L_{s}}
$$

Hence, we can deduce the gains of the PI current regulator:

$$
\left\{\begin{array}{l}
K_{p}=\frac{L_{s} L_{r}-M^{2}}{\tau L_{s}} \\
K_{i}=\frac{R_{r}}{\tau}
\end{array}\right.
$$

Similar development can be done for $T_{e m}$ control, Fig. 7 . The time response of the controlled system is fixed at $\tau=$ $5 m s$. In fact, this value is sufficient in WECS applications.

As we can see, the gains of the controller $K_{p}$ and $K_{i}$, are directly calculated in function of DFIG parameters, if these parameters are varying in time, the robustness of the whole system can be affected. 


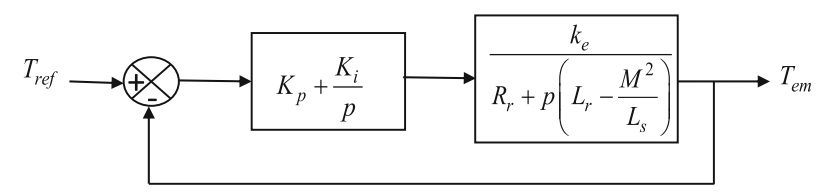

Fig. $7 T_{\text {em }}$ control

\subsection{Sliding mode control}

In our case, we use two sliding surfaces which are defined as follows:

$$
\left\{\begin{array}{l}
S_{1}=I_{r d}-I_{r d-r e f} \\
S_{2}=T_{e m}-T_{r e f}
\end{array}\right.
$$

The derivative of (39):

$$
\left\{\begin{array}{l}
\dot{S}_{1}=\dot{I}_{r d}-\dot{I}_{r d-r e f} \\
\dot{S}_{2}=\dot{T}_{e m}-\dot{T}_{r e f}
\end{array}\right.
$$

Substituting $\dot{I}_{r d}$ and $\dot{T}_{e m}$ by their expressions in Eq. (16), Eq. (40) can be rewritten as:

$$
\left\{\begin{array}{l}
\dot{S}_{1}=\frac{1}{\sigma L_{r}}\left(V_{r d}-R_{r} I_{r d}+s \omega_{s} \sigma L_{r} I_{r q}-\frac{M}{L_{s}} \dot{\phi}_{s d}\right) \\
-\dot{I}_{r d-r e f} \\
\dot{S}_{2}=-n_{p} \frac{M}{\sigma L_{s} L_{r}} \phi_{s d}\left(V_{r q}-R_{r} I_{r q}-s \omega_{s} \sigma L_{r} I_{r d}\right) \\
+s \omega_{s} \frac{M}{L_{s}} \phi_{s d}\left(n_{p} \frac{M}{\sigma L_{s} L_{r}} \phi_{s d}\right)-\dot{T}_{r e f}
\end{array}\right.
$$

Let

$$
\left\{\begin{array}{l}
V_{r d}=V_{r d}^{e q}+V_{r d}^{n} \\
V_{r q}=V_{r q}^{e q}+V_{r q}^{n}
\end{array}\right.
$$

During the sliding phase, in stable state, we have:

$$
\begin{cases}S_{1}=0, & \dot{S}_{1}=0 \\ S_{2}=0, & \dot{S}_{2}=0\end{cases}
$$

Based on system (41) we can compute the equivalent control laws $V_{r d}^{e q}$ and $V_{r q}^{e q}$.

$$
\left\{\begin{aligned}
\dot{S}_{1}= & \frac{1}{\sigma L_{r}}\left(V_{r d}^{e q}-R_{r} I_{r d}+s \omega_{s} \sigma L_{r} I_{r q}-\frac{M}{L_{s}} \dot{\phi}_{s d}\right) \\
& -\dot{I}_{r d-r e f} \\
\dot{S}_{2}= & -n_{p} \frac{M}{\sigma L_{s} L_{r}} \phi_{s d}\left(V_{r q}^{e q}-R_{r} I_{r q}-s \omega_{s} \sigma L_{r} I_{r d}\right) \\
& +s \omega_{s} \frac{M}{L_{s}} \phi_{s d}\left(n_{p} \frac{M}{\sigma L_{s} L_{r}} \phi_{s d}\right)-\dot{T}_{r e f}
\end{aligned}\right.
$$

Using reached condition in (43), we can deduce:

$$
\left\{\begin{array}{l}
V_{r d}^{e q}=R_{r} I_{r d}-s \omega_{s} \sigma L_{r} I_{r q}+\frac{M}{L_{s}} \dot{\phi}_{s d}-\sigma L_{r} \dot{I}_{r d-r e f} \\
V_{r q}^{e q}=R_{r} I_{r q}+s \omega_{s} \sigma L_{r} I_{r d}+s \omega_{s} \frac{M}{L_{s}} \phi_{s d}-\frac{\sigma L_{s} L_{r}}{n_{p} M \phi_{s d}} \dot{T}_{r e f}
\end{array}\right.
$$

The discontinuous term $V^{n}$ contains a "sign" function in its expression, which involve the appearance of the chattering phenomenon, characterized by large oscillations around the sliding surface $S[22,23]$. To minimize the undesirable chattering effect, we replace the function "sign" by a saturation function "sat". Hence, $V^{n}$ can be written as follows:

$$
\left\{\begin{array}{l}
V_{r d}^{n}=k_{1} \operatorname{sat}\left(S_{1}\right) \\
V_{r q}^{n}=k_{2} \operatorname{sat}\left(S_{2}\right)
\end{array}\right.
$$

Then, the global control law is written as:

$$
\left\{\begin{array}{l}
V_{r d}=R_{r} I_{r d}-s \omega_{s} \sigma L_{r} I_{r q}+\frac{M}{L_{s}} \dot{\phi}_{s d}-\sigma L_{r} \dot{I}_{r d-r e f}+k_{1} s a t\left(S_{1}\right) \\
V_{r q}=R_{r} I_{r q}+s \omega_{s} \sigma L_{r} I_{r d}+s \omega_{s} \frac{M}{L_{s}} \phi_{s d}-\frac{\sigma L_{s} L_{r}}{n_{p} M \phi_{s d}} \dot{T}_{r e f}+k_{2} s a t\left(S_{2}\right)
\end{array}\right.
$$

First order sliding mode technique can cope with system uncertainty and improve the performance of the system However, it generates undesirable chattering due to its discontinuous control $V_{n}$.

\subsection{Second order sliding mode control}

An effective method to overcome the Chattering problem is to use a high order sliding control, Fig. 8. In fact, a control order $\mathrm{n}$ acts on $\mathrm{n}$ derivatives. This feature helps mitigate the effect of chattering while

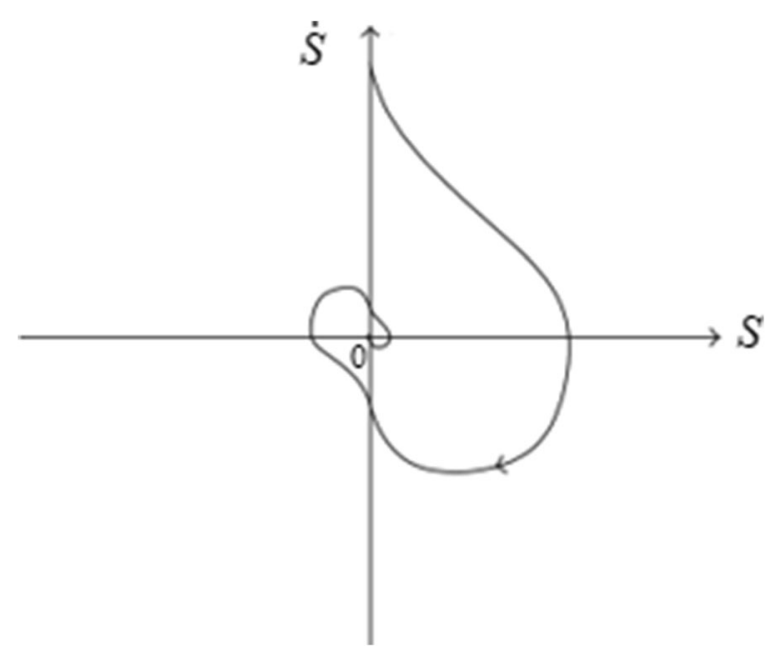

Fig. 8 Phase plane trajectory of STW algorithm 
Table 1 WT-DFIG parameters

\begin{tabular}{ll}
\hline Nominal power & $P_{n}=1.5 \mathrm{MW}$ \\
Turbine rayon $(\mathrm{m})$ & $R=35$ \\
$\mathrm{WT}$ inertia $(\mathrm{kg} . \mathrm{m} 2)$ & $J=4.4532 e^{5}$ \\
Air density (kg.m3) & $\rho=1.225$ \\
Gear reduction ratio & $n_{g}=73$ \\
Stator resistance $(\Omega)$ & $R_{s}=12 e^{-3}$ \\
Rotor resistance $(\Omega)$ & $R_{r}=21 e^{-3}$ \\
Stator inductance $(H)$ & $L_{s}=13.7 e^{-3}$ \\
Rotor inductance $(H)$ & $L_{r}=13.67 e^{-3}$ \\
Cyclic inductance $(H)$ & $M=12.2 e^{-3}$ \\
Pole pairs & $n_{p}=2$
\end{tabular}

preserving the robust properties of the sliding mode approach [29, 30].

However, the implementation of an $n$ order controller requires the knowledge of " $n-1$ " consecutive time derivatives of the sliding surface, $\dot{S}, \ddot{S}, . . S^{(n-1)}$. STW strategy presents an exception since it needs only information on sliding surface $S$. Hence, the complexity of the controller is reduced.

The error system and its derivative are given by Eqs. (34) and (36) respectively.

Let consider the functions $G_{1}$ and $G_{2}$ as follows:

$$
\left\{\begin{aligned}
G_{1}= & \frac{1}{\sigma L_{r}}\left(-R_{r} I_{r d}+s \omega_{s} L_{r} \sigma I_{r q}-\frac{M}{L_{s}} \dot{\phi}_{s d}\right)-\dot{I}_{r d r e f} \\
G_{2}= & -n_{p} \frac{M}{\sigma L_{s} L_{r}} \phi_{s}\left(-R_{r} I_{r q}-s \omega_{s} L_{r} \sigma I_{r d}\right) \\
& +s \omega_{s} \frac{M}{L_{s}} \phi_{s d}\left(n_{p} \frac{M}{\sigma L_{s} L_{r}} \phi_{s}\right)-\dot{T}_{r e f}
\end{aligned}\right.
$$

We assume that $G_{1}$ and $G_{2}$ are bounded functions that satisfy the following conditions:

$$
\left\{\begin{array}{l}
\left|G_{1}\right| \leq q_{1}\left|S_{1}\right|^{1 / 2} \\
\left|G_{2}\right| \leq q_{2}\left|S_{2}\right|^{1 / 2}
\end{array}\right.
$$

where, $q_{1}, q_{2}$ are positive constants.

Then, we can write:

$$
\left\{\begin{array}{l}
\dot{S}_{1}=\frac{1}{\sigma L_{r}} V_{r d}+G_{1} \\
\dot{S}_{2}=-n_{p} \frac{M}{\sigma L_{s} L_{r}} \phi_{s d} V_{r q}+G_{2}
\end{array}\right.
$$

The STW control laws are:

$$
\left\{\begin{array}{l}
V_{r d}=y_{1}-c_{1}\left|S_{1}\right| 1 / 2 \operatorname{sgn}\left(S_{1}\right) \\
\dot{y}_{1}=-c_{2} \operatorname{sgn}\left(S_{1}\right) \\
V_{r q}=y_{2}+c_{3}\left|S_{2}\right|^{1 / 2} \operatorname{sgn}\left(S_{2}\right) \\
\dot{y}_{2}=+c_{4} \operatorname{sgn}\left(S_{2}\right)
\end{array}\right.
$$

where $V_{r d}$ controls the reactive power through the current $I_{r d}$ and $V_{r q}$ controls the active power through the electromagnetic torque $T_{e m}$.

By substituting the expression of $V_{r d}$ in system (51) into (50), we obtain:

$$
\begin{aligned}
& \left\{\begin{array}{l}
\dot{S}_{1}=-\lambda_{1} c_{1}\left|S_{1}\right| 1 / 2 \operatorname{sgn}\left(S_{1}\right)+\varphi+G_{1} \\
\dot{\varphi}=-\lambda_{1} c_{2} \operatorname{sgn}\left(S_{1}\right)
\end{array}\right. \\
& \lambda_{1}=\frac{1}{\sigma L_{r}}, \varphi=\lambda_{1} y_{1}
\end{aligned}
$$

The proof of the stability analysis of system (52) takes place in two stages: In the first step, we will rewrite system (52) in a more convenient form for the Lyapunov analysis by introducing the following new vector:

$$
z=\left[\begin{array}{ll}
z_{1} & z_{2}
\end{array}\right]^{T}=\left[\left|S_{1}\right|^{1 / 2} \operatorname{sign}\left(S_{1}\right) \quad \phi\right]^{T}
$$

We can easily deduce the derivative of Eq. (53):

$$
\left\{\begin{array}{l}
\dot{z}_{1}=\frac{1}{\left|z_{1}\right|}\left(-\frac{\lambda_{1} c_{1}}{2} z_{1}+\frac{1}{2} z_{2}+\frac{1}{2} G_{1}\right) \\
\dot{z}_{2}=-\frac{\lambda_{1} c_{2}}{\left|z_{1}\right|} z_{1}
\end{array}\right.
$$

From Eqs. (49) and (53), we get:

$$
G_{1}(x, t)=\delta_{1}(x, t)\left|S_{1}\right|^{1 / 2} \operatorname{sgn}\left(S_{1}\right)=\delta_{1}(x, t) z_{1}
$$

with $\delta_{1}(x, t)$ is a bounded function so that: $0<\delta_{1}(x$, t) $\leq q_{1}$.

System (54) becomes:

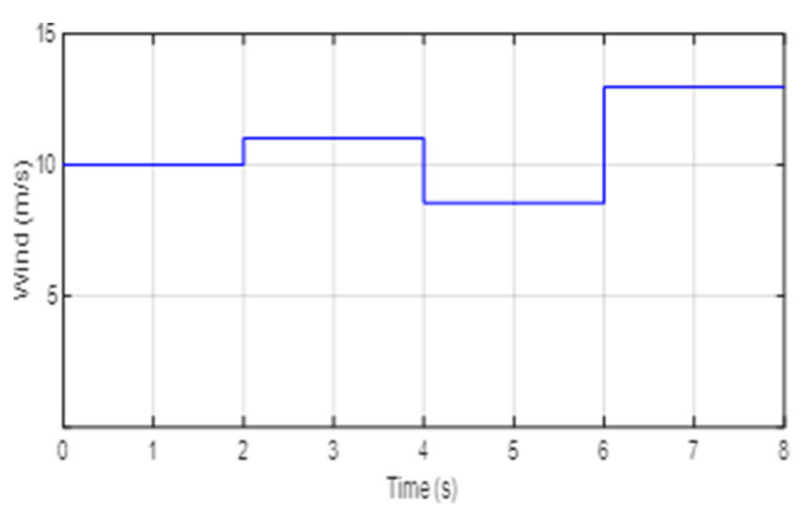

Fig. 9 Wind speed profile $(\mathrm{m} / \mathrm{s})$ 


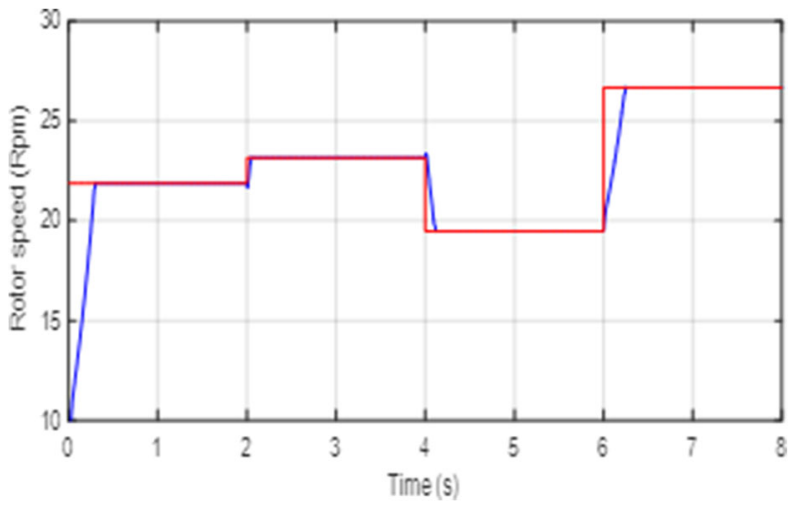

Fig. $10 \mathrm{WT}$ rotor speed tracking: reference (red) and real (blue)

$$
\left[\begin{array}{c}
\dot{z}_{1} \\
\dot{z}_{2}
\end{array}\right]=\frac{1}{2\left|z_{1}\right|}\left[\begin{array}{crc}
-\lambda_{1} c_{1}+\delta_{1}(x, t) & 1 \\
-\lambda_{1} c_{2} & 0
\end{array}\right]\left[\begin{array}{l}
z_{1} \\
z_{2}
\end{array}\right]
$$

Then, we can write:

$$
\dot{z}=A\left(z_{1}, z_{2}\right) z
$$

where

$$
A\left(z_{1}, z_{2}\right)=\frac{1}{2\left|z_{1}\right|}\left[\begin{array}{ccc}
-\lambda_{1} c_{1}+\delta_{1}(x, t) & 1 \\
-\lambda_{1} c_{2} & 0
\end{array}\right]
$$

In the second step of the proof, the stability analysis of Eq. (52), can be proved using Lyapunov approach.

Let's consider the following candidate Lyapunov function:

$$
V(z)=z^{T} P z
$$

with $P$ is a symmetric positive definite matrix which is a solution of the following equation:

$$
A^{T} P+P A<0
$$

The derivative of Eq. (58) is:

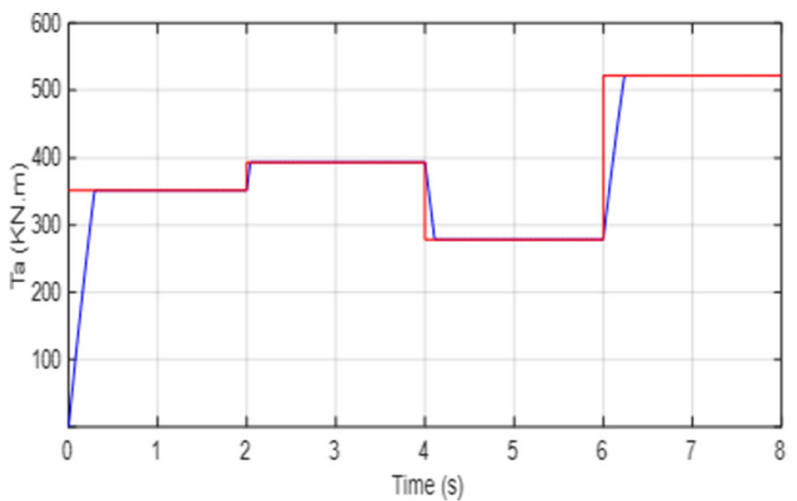

Fig. 11 Aerodynamic torque estimation

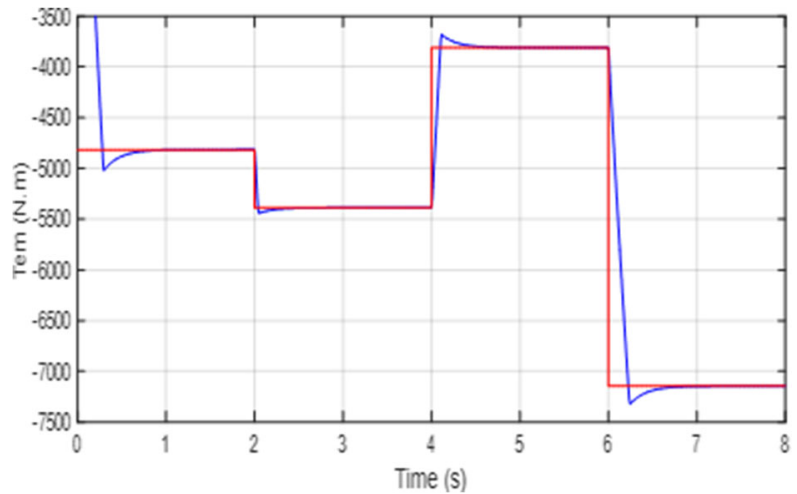

Fig. 12 Electromagnetic torque tracking performance for $\mathrm{PI}$ controller

$$
\dot{V}(z)^{T}=z^{T}\left[A^{T} P+P A\right] z
$$

By choosing matrix $P$ as follows:

$$
P=\left[\begin{array}{cc}
\lambda_{o}+4 \varepsilon^{2} & -2 \varepsilon \\
-2 \varepsilon & 1
\end{array}\right]
$$

where, $\lambda_{o}$ and $\varepsilon$ are positives constants.

We can write:

$$
\dot{V}(z)^{T} \leq-\frac{1}{2\left|z_{1}\right|} z^{T} Q z
$$

where $Q$ is a symmetric matrix:

$$
Q=\left[\begin{array}{ll}
Q_{11} & Q_{12} \\
Q_{21} & 4 \varepsilon
\end{array}\right]
$$

with

$$
\left\{\begin{array}{l}
Q_{11}=2 \lambda_{0} \lambda_{1} c_{1}+4 \varepsilon \lambda_{1}\left(2 \varepsilon c_{1}-c_{2}\right)-2 \delta_{1}(x, t)\left(\lambda_{0}+4 \varepsilon^{2}\right) \\
Q_{12}=Q_{21}=\left(\lambda_{1} c_{2}-2 \varepsilon \lambda_{1} c_{1}-\lambda_{0}-4 \varepsilon^{2}\right)+2 \varepsilon \delta_{1}(x, t) .
\end{array}\right.
$$

If the controller gains satisfy the following inequalities:

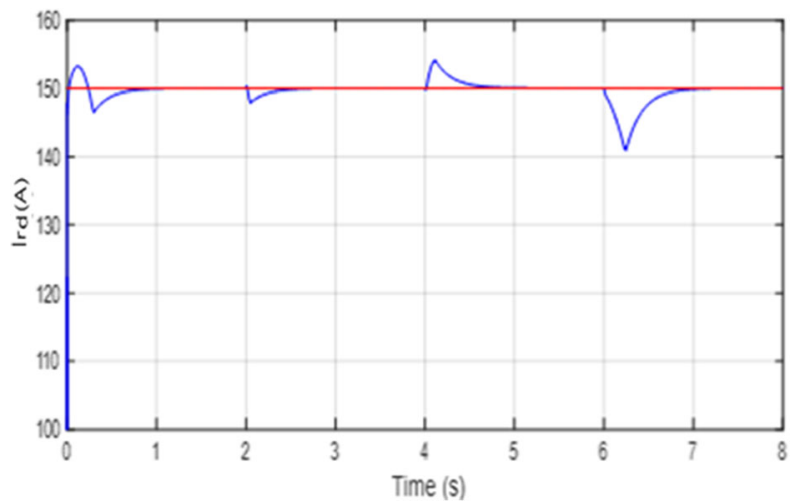

Fig. 13 Current tracking performance for PI controller 


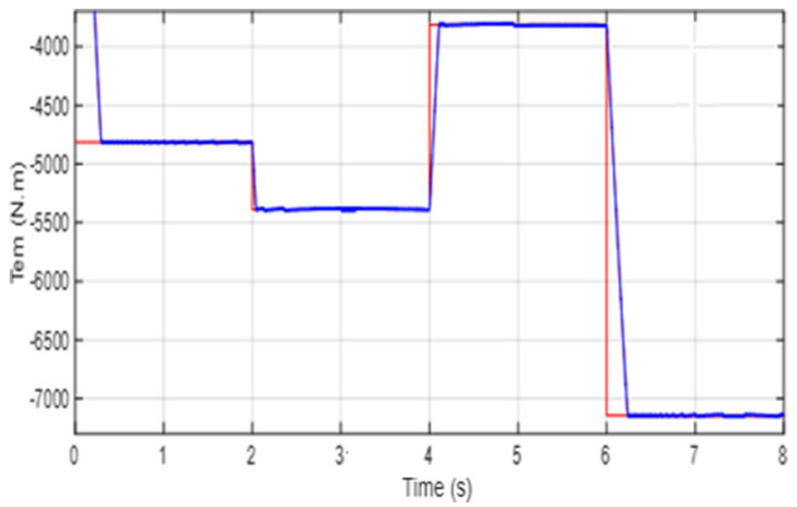

Fig. 14 Electromagnetic torque tracking performance for SMC

$$
\left\{\begin{array}{l}
c_{1}>\frac{\sigma L_{r} q_{1}\left(\lambda_{o}+4 \varepsilon^{2}\right)+2 \varepsilon\left(\lambda_{o}+\varepsilon^{2}\right)}{\lambda_{o}} \\
c_{2}=2 \varepsilon c_{1}+\lambda_{0}+4 \varepsilon^{2}
\end{array}\right.
$$

Then, $Q \succ 0$, implying that the derivative of the Lyapunov function is negative:

$$
\dot{V}(z) \leq-\frac{1}{2\left|z_{1}\right|} z^{T} Q z<0
$$

Similar development can be used in the case $V_{r q}$ to prove the stability and the convergence of sliding surfa$\mathrm{ce} S_{2}$ to zero.

\section{Simulation results and discussion}

In this section, the simulation study has been carried out using MATLAB environment with variable wind speed profile from 8 to $13 \mathrm{~m} / \mathrm{s}$. The generator is performed with PI regulators, SMC and STW algorithm respectively. Two types of tests have been fulfilled to evaluate the reference tracking performance and the robustness of the control. Wind turbine and DFIG parameters are summarized in Table 1.

Reference tracking:

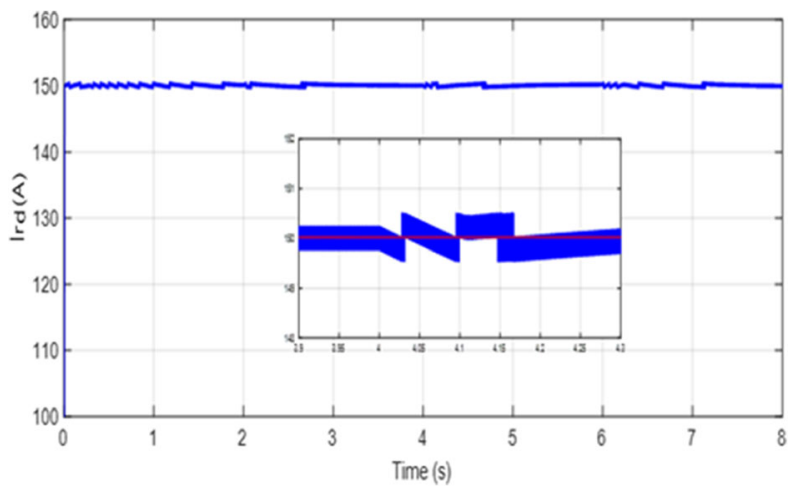

Fig. 15 Current tracking performance for SMC

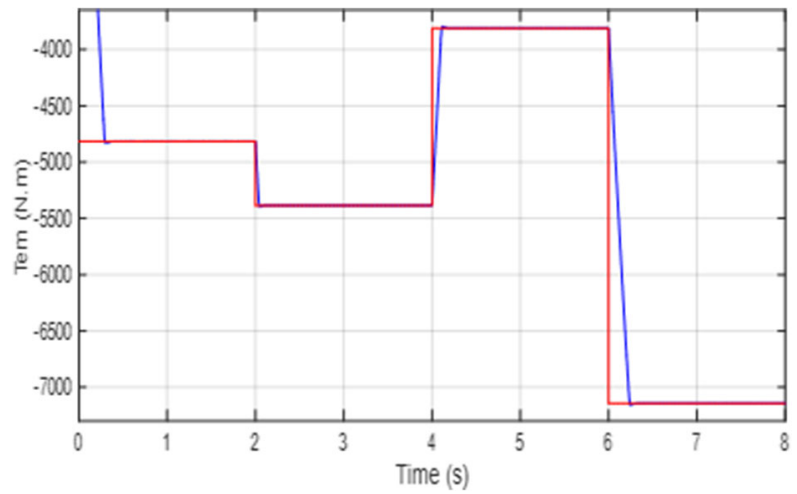

Fig. 16 Electromagnetic torque tracking performance for STW

The wind speed is composed of several patterns which vary from 8 to $13 \mathrm{~m} / \mathrm{s}$ as shown in Fig. 9. Through this first test we will evaluate the performance of STW control of the turbine. Also, we compare the responses of three types of controllers applied to the DFIG. The simulation results show good tracking rotational speed performance achieved with aerodynamic torque estimation Figs. 10 and 11. The simulation results of PI, SMC and STW are presented in Figs. 12, 14, and 16 respectively under different electromagnetic torque variations. The maximum variation is observed at $t=$ $6 \mathrm{~s}$ (from $-3.8 \mathrm{kN} . \mathrm{m}$ with $8 \mathrm{~m} / \mathrm{s}$ of wind speed to -7.2 $\mathrm{kN} . \mathrm{m}$ with $12 \mathrm{~m} / \mathrm{s}$ respectively). The results show that the electromagnetic torque and the rotor current tracking references are reached using PI, SMC and STW. The PI results in Figs. 12 and 13 show an overshoot, high current ringing during torque variation and some dynamic errors. Simulation results with first order SMC given in Figs. 14 and 15 present a good reference tracking and transient performances without any specific overshooting or dynamic errors compared to PI controllers. However, it is also observed that SMC generates undesirable chattering due to its

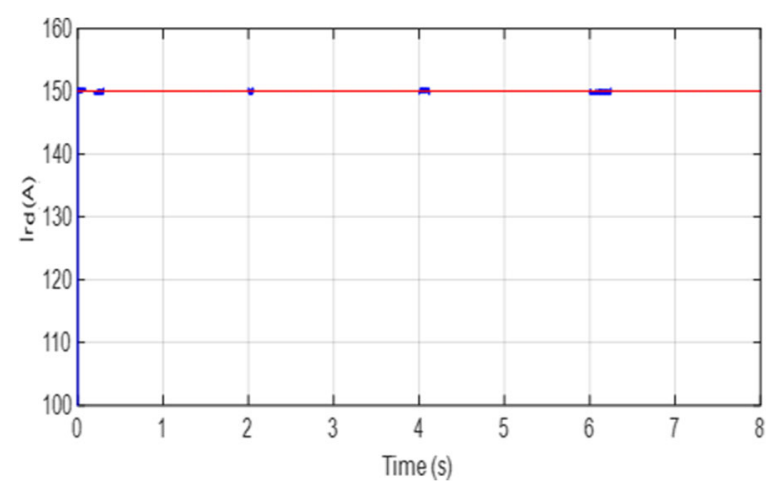

Fig. 17 Current tracking performance for STW 


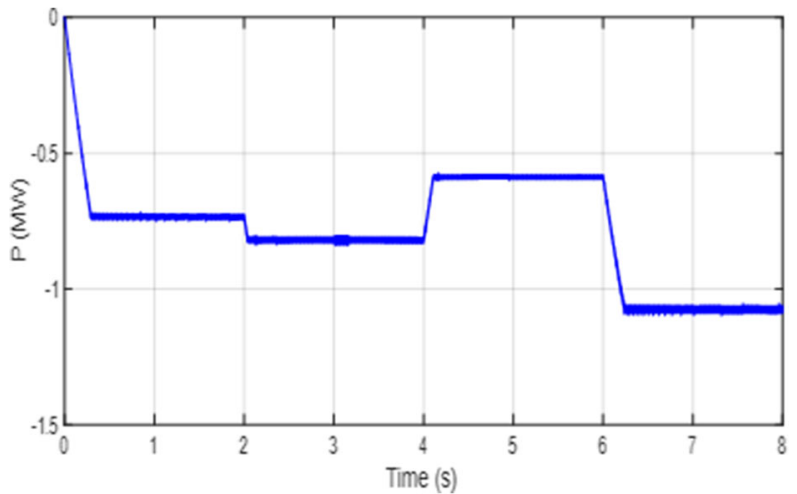

Fig. 18 DFIG stator active power with SMC

discontinuous term $V^{n}$ which affect the performances of the system, as shown in Fig. 15. On the other hand, STW's results shown in Figs. 16 and 17 present better tracking performances of electromagnetic torque and rotor current compared to PI and SMC. The proposed STW succeeded to overcome the problem of undesirable chattering whilst preserving the features of SMC.

Figures 18 and 19, present the stator active power of the DFIG with SMC and STW respectively, we can deduce the performance of STW strategy and the negative effect of chattering of conventional SMC on the quality of the generated power in steady state.

\section{- Robustness tests}

The robustness of STW algorithm during static and transient regimes will be checked through this test with DFIG parameters variations. Rotor resistance and mutual inductance of the machine may change due to variation in the permeability of the stator and rotor under different operating conditions. Therefore, those variation should be considered in order to evaluate the robustness of the controller: rotor resistance and mutual inductance are varied $\pm 50 \%$ from their nominal values, as shown in Fig. 20. We

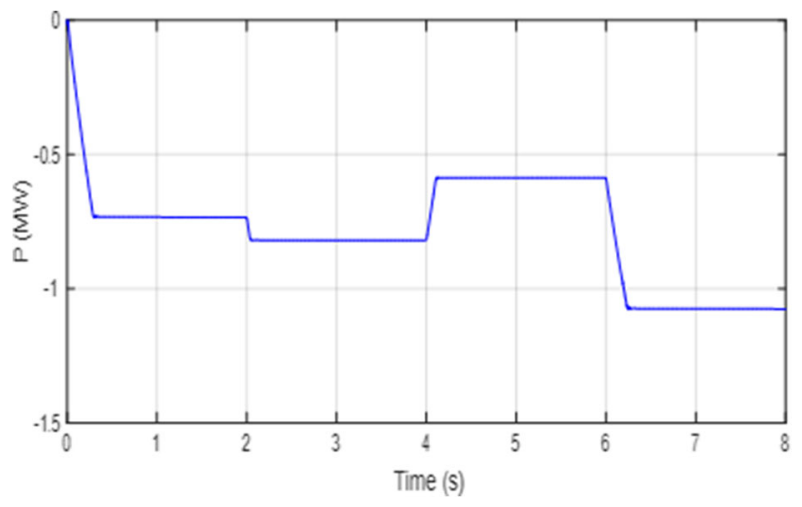

Fig. 19 DFIG stator active power with STW

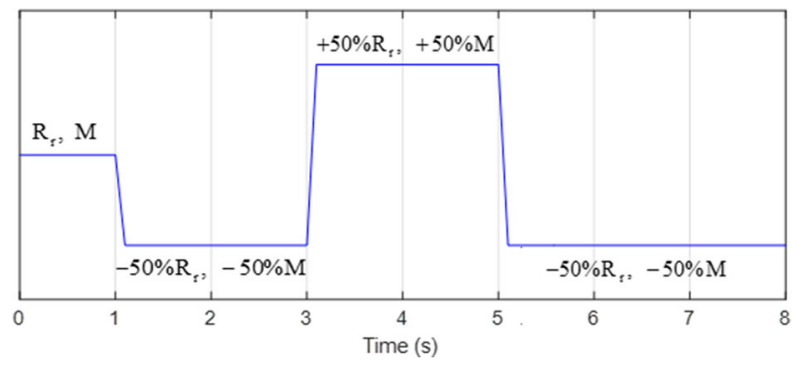

Fig. 20 Rotor resistance and mutual inductance variations

can observe the effect of DFIG parameter variations on the power generation in Fig. 21. The effect of this variations are more important on PI controller with high overshooting while there are no perturbations with STW algorithm. Hence, we can conclude the robustness of the STW algorithm and its performance compared to the two others controllers in this work.

\section{Conclusion}

This paper describes a robust control based on sliding mode for aerodynamic torque estimation to maximize wind energy extraction for a variable speed wind turbine. Three different controllers for the DFIG are developed and compared, in term of current and electromagnetic torque reference tracking and robustness. When the wind speed is varied, the effect on rotor direct current (control the reactive power) and electromagnetic torque (control the active power) values are much important with PI than SMC while it is without effect with STW control.

Although deceptively simple, PI control strategy has serious drawbacks that make it unsuitable for many practical applications. The comparison done in this work shows the limits of this controller with sensitivity to parameter variations and transient response, under high wind speed variations which can have negative effects on

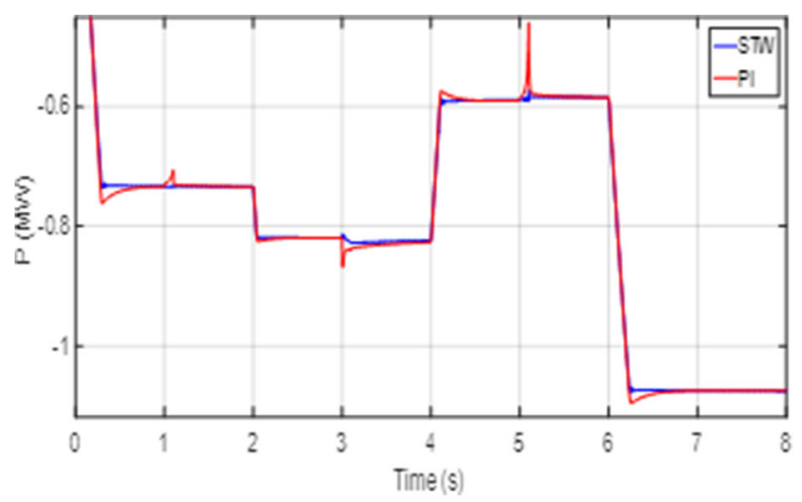

Fig. 21 DFIG stator active power 
the quality and the quantity of the generated power. The results presented show that a sliding mode control method can be an interesting solution for system based on DFIG configuration for wind power conversion. However, chattering effect remains a significant problem with this technique. The obtained results show that STW strategy effectiveness is more attractive in terms of power extraction maximization, energy quality and higher accuracy, compared to more traditional techniques PI and classic SMC.

\section{Abbreviations}

DFIG: Doubly fed induction generator; PI: Proportional integral; SMC: Sliding mode control; SOSMC: Second order sliding mode; STW: Super Twisting; WECS: Wind energy conversion system; WT: Wind turbine

\section{Authors' contributions}

SB as a corresponding author, contributed significantly to analysis, manuscript preparation and manuscript submission. HA, AEh and MC as supervisors helped to perform the study analysis with constructive discussions, professional advice and revised the manuscript. All authors read and approved the final manuscript.

\section{Ethics approval and consent to participate}

Not applicable.

\section{Consent for publication}

Not applicable.

\section{Competing interests}

The authors declare that they have no competing interests.

Received: 8 February 2018 Accepted: 13 June 2018

Published online: 05 July 2018

\section{References}

1. Wu, B., Lang, Y., Zargari, N., \& Kouro, S. (2011). Power conversion and control of wind energy systems. United States of America: John Wiley \& Sons, Inc..

2. Muneer, A., Bilal-Kadri, M. (2013). Pitch angle control of DFIG using selftuning neuro fuzzy controller. 2nd International Conference on Renewable Energy Research and Applications (ICRERA), Madrid, Spain, 20-23.

3. Tapia, A., Tapia, G., Ostolaza, J. X., \& Saenz, J. R. (2003). Modeling and control of a wind turbine driven doubly fed induction generator. IEEE Transactions on energy conversion, 18(2), 194-204.

4. Aydin, E., Polat, A., Ergene, L.T. (2016). Vector control of DFIG in wind power applications. 5th international conference on renewable energy research and applications (ICRERA), Birmingham, UK, 20-23.

5. Arnalte, S., Burgos, J. C., \& Rodriguez-Amenedo, J. L. (2002). Direct torque control of a doubly-fed induction generator for variable speed wind turbines. Electric power components and systems, 30(2), 199-216.

6. Amar, A. B. (2017). Direct torque control of a doubly fed induction generator. International Journal of Energetica, 2(1), 11-14.

7. Abad, G., Rodriguez, M. A., Iwanski, G., \& Poza, J. (2010). Direct power control of doubly-fed-induction-generator-based wind turbines under unbalanced grid voltage. IEEE Trans Power Electron, 25(2), 442-452.

8. Vidal, Y., Acho, L., Luo, N., Zapateiro, M., \& Pozo, F. (2012). Power control design for variable-speed wind turbines. Energies, 5, 3033-3050.

9. Broy, A., Tourou, P., Sourkounis, C. (2015). Transient behaviour and active damping of vibrations in DFIG-based wind turbines during grid disturbances. 4th International Conference on Renewable Energy Research and Applications (ICRERA), Italy, 22-25.

10. Giaourakis, D., Safacas, A., \& Tsotoulidis, S. (2012). Dynamic behaviour of a wind energy conversion system including doubly-fed induction generator in fault conditions. International Journal of Renewable Energy Research, 2(2), 227-235.

11. Mohamed, Z., Eskander, M., \& Ghali, A. (2001). Fuzzy logic control based maximum power tracking of a wind energy system. Renew Energy, 23(2), $235-245$.
12. Lpez, P., Velo, R., \& Maseda, F. (2008). Effect of direction on wind speed estimation in complex terrain using neural networks. Renew Energy, 33(10), 2266-2272.

13. Hostettler, J., \& Wang, X. (2015). Sliding mode control of a permanent magnet synchronous generator for variable speed wind energy conversion systems. Journal Systems Science \& Control Engineering, 3, 453-459.

14. Bourdoulis, M., Alexandridis, A. (2013). Rotor-side PI controller design of DFIG wind turbines based on direct power flow modeling, 2nd International Conference on Renewable Energy Research and Applications (ICRERA), Madrid, Spain, 20-23.

15. Sguarezi, A., \& Ruppert, E. (2012). Model-based predictive control applied to the doubly-fed induction generator direct power control. IEEE Trans Sustain Energy, 3, 398-406.

16. Verij, K. M., Sadeghi, Y. A., \& Kojabadi, H. K. (2010). Direct power control of DFIG based on discrete space vector modulation. Renew Energy, 35(5), 1033-1042.

17. Chikha, S., \& Barra, K. (2016). Predictive control of variable speed wind energy conversion system with multi objective criterions. Periodica Polytechnica. Electrical Engineering and Computer Science, 60(2), 96.

18. Barambones, O. (2012). Sliding mode control strategy for wind turbine power maximization. Energies, 5, 2310-2330.

19. Khedher, A., Khemiri, N., \& Mimouni, M. (2012). Wind energy conversion system using DFIG controlled by Backstepping and sliding mode strategies. International Journal of Renewable Energy Research, 2(3), 421-430.

20. Taraft, S., Rekioua, D., Aouzellag, D., \& Bacha, S. (2015). A proposed strategy for power optimization of a wind energy conversion system connected to the grid. Journal of Energy Conversion and Management, 101, 489-502.

21. Beltran, B., \& Benbouzid, A. (2012). Second-order sliding mode control of a doubly fed induction generator driven wind turbine. IEEE Transactions on Energy Conversion, 27(261-269), 2012.

22. Utkin, V. (1993). Sliding mode control design principles and applications to electric drives. IEEE Trans Ind Electron, 40(1), 23-36.

23. Slotine, J., \& Li, W. (1998). Applied nonlinear control. USA: Prentice Hall.

24. Rivera, J., Garcia, L., Mora, C., Ortega, S. (2011). Super-twisting sliding mode in motion control systems, Sliding Mode Control, InTech, https://www. intechopen.com/books/sliding-mode-control/super-twisting-sliding-modein-motion-control-systems.

25. Poitiers, F., Bouaouiche, T., \& Machmoum, M. (2009). Advanced control of a doubly-fed induction generator for wind energy conversion. Elect Power Syst Res, 79(7), 1085-1096.

26. Abdelhafidh, M., Mahmoudi, M., Nezli, L., \& Bouchhida, O. (2012). Modeling and control of a wind power conversion system based on the double-fed asynchronous generator. International Journal of Renewable Energy Research, 2(2), 300-306

27. Adjoudj, M., Abid, M., Aissaoui, A., Ramdani, Y., \& Bounoua, H. (2011). Sliding mode control of doubly fed induction generator for wind energy turbine. Rev Roum SciTechn-Électrotechn et Énerg, Bucarest, 56, 15-24.

28. Miranda, H., Cortes, P., \& Yuz, J. (2009). Predictive torque control of induction machines based on state space models. IEEE Trans Ind Electron, 56(6), 1916-1924.

29. Beltran, B., Ahmed-Ali, T., \& Benbouzid, M. (2008). Sliding mode power control of variable-speed wind energy conversion systems. IEEE Transactions on energy conversion, 23(2), 551-558.

30. Valenciaga, F., \& Puleston, F. (2008). High-order sliding control for a wind energy conversion system based on a permanent magnet synchronous generator. IEEE Transactions on Energy Conversion, 23(3), 860-867.

\section{Submit your manuscript to a SpringerOpen ${ }^{\circ}$ journal and benefit from:}

- Convenient online submission

- Rigorous peer review

- Open access: articles freely available online

- High visibility within the field

- Retaining the copyright to your article

Submit your next manuscript at $>$ springeropen.com 